\title{
May modifications of human plasma proteins stimulated by homocysteine and its thiolactone induce changes of hemostatic function of plasma in vitro?
}

\author{
Beata Olas, Joanna Kołodziejczyk and Joanna Malinowska \\ Department of General Biochemistry, Institute of Biochemistry, University of Łódź, Banacha 12/16, 90-237 Łódź, Poland
}

\begin{abstract}
Homocysteine (Hcys) may be implicated in different diseases, especially in cardiovascular illnesses. The most reactive form of Hcys is its cyclic thioester - homocysteine thiolactone (HTL), which is formed in plasma and represents up to $0.29 \%$ of plasma total Hcys. Recently, it has been observed that Hcys and HTL may modify plasma proteins, including albumin, hemoglobin or fibrinogen, but the role of this process is not yet well known. The aim of our study in vitro was to investigate the modifications of human plasma total proteins after incubation with the reduced form of Hcys in concentrations 10-100 $\mu \mathrm{mol} / \mathrm{l}$, and HTL in concentrations 1-0.1 $\mu \mathrm{mol} / \mathrm{l}$, which correspond to levels found in human plasma during hyperhomocysteinemia in vivo. The aim of our study was also to explain the effects of Hcys and HTL on coagulation activity of human plasma. We showed that in model system in vitro Hcys and HTL change the level of thiol, amino and carbonyl groups in plasma total proteins. Moreover, our studies reported that not only Hcys (10-100 $\mu \mathrm{mol} / \mathrm{l}$ ), but also HTL (at lower concentrations than Hcys) modulates the coagulation properties of human plasma.
\end{abstract}

Key words: Homocysteine - Homocysteine thiolactone - Plasma - Proteins

Abbreviations: Hcys, homocysteine; HTL, homocysteine thiolactone; LDL, low density lipoproteins; Lys, lysine.

\section{Introduction}

L-Homocysteine (Hcys) is an endogenous amino acid, containing free thiol group, which in healthy cells is involved in methionine and cysteine synthesis/resynthesis. Indirectly, Hcys participates in methyl, folate, and cellular thiols metabolism (D’Angelo and Selhub 1997). Approximately 80\% of plasma Hcys is protein bound, and only a small amount exists as a free reduced Hcys (about $100 \mathrm{nmol} / \mathrm{l}$ ). The majority of the unbound portion of Hcys is oxidized to form dimers (homocystine) or combined with cysteine to form mixed disulphides (Mansoor et al. 1992; Ramakrishnan et al. 2006). The excess of Hcys concentration is described in many human pathologies, including neurodegenerative diseases (Ravaglia et al. 2005), thrombosis (Harpel et al. 1996)

Correspondence to: Beata Olas, Department of General Biochemistry, Institute of Biochemistry, University of Łódź, Banacha 12/16, 90-237 Łódź, Poland

E-mail: olasb@biol.uni.lodz.pl and thrombosis-related diseases, like stroke (Boysen et al. 2003; Li et al. 2003).

Recently, two main pathways of Hcys biotoxicity are discussed: 1) Hcys-dependent oxidative stress and 2) Hcysinduced protein structure modifications named homocysteinylation. In the first case, oxidative stress is generated during oxidation of free thiol group of Hcys, when Hcys binds via disulphide bridge with plasma proteins - mainly albumin, or with another low-molecular plasma thiols or with second Hcys molecule. Oxidation of Hcys may induce in further oxidation of proteins, lipids and nucleic acids (Zou and Banerjee 2005). Accumulation of oxidized biomolecules alters functions of many cellular pathways. In the second case, two main types of homocysteinylation exist, which can be considered as posttranslational protein modifications: S-homocysteinylation and N-homocysteinylation. S-homocysteinylation occurs when Hcys reacts by its free thiol group or with another free thiol derived from cysteine of protein molecules. These changes can alter thiol-dependent redox status of protein (Sengupta et al. 2001). N-homocysteinyla- 
tion take places after acylation of free $\varepsilon$-amino group of protein by Hcys, or the most reactive form of Hcys - its cyclic thioester (Hcys thiolactone (HTL)), which represent up to $0.29 \%$ of plasma total Hcys (Jakubowski 1999; PerlaKajan et al. 2007).

In human blood N-homocysteinylated (N-Hcys-protein) or S-homocysteinylated proteins (S-Hcys-protein) were described as N-Hcys-hemoglobin, N-(Hcys-S-S-Cys)-albumin, S-Hcys-albumin, and cysteinylhomocysteine (Cys-Hcys) (Jakubowski 2002, 2006; Chwatko and Jakubowski 2005a,b; Perla-Kajan et al. 2007).

The aim of this study in vitro was investigate the modifications of human plasma total proteins after incubation with L-Hcys and HTL in different times (5-60 min). We checked changes in thiol, amino and carbonyl groups content as a sign of S-, N-homocysteinylation and oxidative damages, respectively. We used the reduced form of Hcys in concentrations $10-100 \mu \mathrm{mol} / \mathrm{l}$, and HTL in concentrations $1-0.1$ $\mu \mathrm{mol} / \mathrm{l}$, which correspond to levels found in human plasma during hyperhomocysteinemia in vivo. Moreover, the aim of our study was to explain the effects of Hcys and HTL on coagulation activity of human plasma.

\section{Material and Methods}

\section{Materials}

Reduced form of L-Hcys and L-homocysteine thiolactone were purchased from Sigma (St. Louis, MO, USA). All other reagents were of analytical grade and were provided by commercial suppliers.

\section{Isolation of plasma}

Blood samples were taken from 8 healthy volunteers (aged between 26-32 years (mean $28.7 \pm 2.1$ )) without cardiovascular disorders, allergy and lipid or carbohydrate metabolism disorders, untreated with drugs. Healthy subjects did not use addictive substances and antioxidant supplementation, their diet was balanced (meat and vegetables), lived in similar socio-economic conditions. Subjects with significant medical illness were excluded. They were no smokers.

Human blood was collected into sodium citrate $(5 \mathrm{mmol} / \mathrm{l}$ final concentration) and immediately centrifuged $(2000 \times g$, $15 \mathrm{~min}$ ) to get plasma. The natural concentration of total Hcys in plasma was $8-14 \mu \mathrm{mol} / \mathrm{l}$. The endogenous concentration of reduced form of Hcys and HTL was about $100 \mathrm{nmol} / \mathrm{l}$ and $0-35 \mathrm{nmol} / \mathrm{l}$, respectively. The classical technique HPLC has been used to analysis of Hcys or HTL in human plasma. The HPLC analysis was performed with a Hewlett-Packard 1100 Series system according to Głowacki et al. (2001) and
Bald et al. (2004). Human plasma was incubated with the reduced form of L-Hcys (at final doses of 10-100 $\mu \mathrm{mol} / \mathrm{l}$ ) or with L-Hcys HTL $(0.1-1 \mu \mathrm{mol} / \mathrm{l})$ for following times: 5, 30 and $60 \mathrm{~min}$, at $37^{\circ} \mathrm{C}$.

\section{Detection of thiol groups in plasma proteins}

The amount of free thiol groups was estimated with 5,5'dithio-bis(2-nitro-benzoic acid) (Ando and Steiner 1973a,b) in plasma diluted 5 times with $0.9 \% \mathrm{NaCl}$. Amount of free thiol groups was estimated using molar extinction coefficient $\left(13600 \mathrm{M}^{-1} \cdot \mathrm{cm}^{-1}\right)$.

\section{Detection of E-amino groups of lysine (Lys) in plasma proteins}

Free $\varepsilon$-amino groups of Lys in plasma proteins were measured spectrophotometrically after reaction with 2,4,6-trinitrobenzene 1-sulfonic acid (TNBS) reagent according to Sashidhar et al. (1994). $250 \mu \mathrm{l}$ of $4 \% \mathrm{NaHCO}_{3}$ and $250 \mu \mathrm{l}$ TNBS were added to $250 \mu \mathrm{l}$ of plasma. Mixture was incubated for 2 hours at $42^{\circ} \mathrm{C}$. After termination of incubation, $250 \mu \mathrm{l}$ of $10 \%$ SDS and $125 \mu \mathrm{l} \mathrm{mol} / \mathrm{l} \mathrm{HCl}$ were added. Absorbance was measured at $335 \mathrm{~nm}$. Number of free amino groups of Lys was estimated on the basis of standard curve made for Lys.

\section{Detection of carbonyl groups in plasma proteins}

Detection of carbonyl groups by spectrophotometric method in plasma (control, Hcys and HTL) after reaction with 2,4dinitrophenylhydrazine (DNPH) was carried out according to Levine et al. (2000), and carbonyl groups content was estimated on the basis of molar extinction coefficient $\left(22000 \mathrm{M}^{-1} \cdot \mathrm{cm}^{-1}\right)$.

\section{Measurements of thrombin and prothrombin time}

The thrombin and prothrombin time were determined coagulometrically (Optic Coagulation Analyser model K-3002; Kselmed, Grudziadz, Poland).

\section{Data analysis}

The statistical analysis was done by several tests. All the values in this study were expressed as mean $\pm \mathrm{SD}$. In order to eliminate uncertain data, Grubbs test or Q-Dixon test were performed. The difference between variations and means were assessed by applying the Fisher-Snedecor test and the unpaired Student's $t$-test, respectively. The statistical analysis was also performed with ANOVA I test using StatSoft Inc. "Statistica" v. 6.0. In the present study we accepted the differences with $p<0.05$ as statistically significant. 


\section{A}

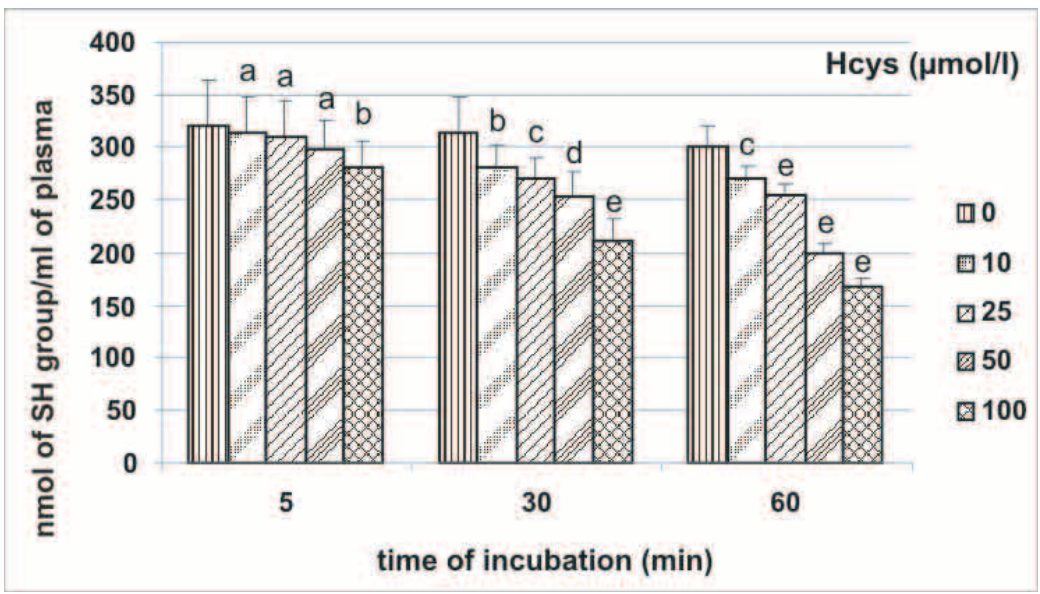

B

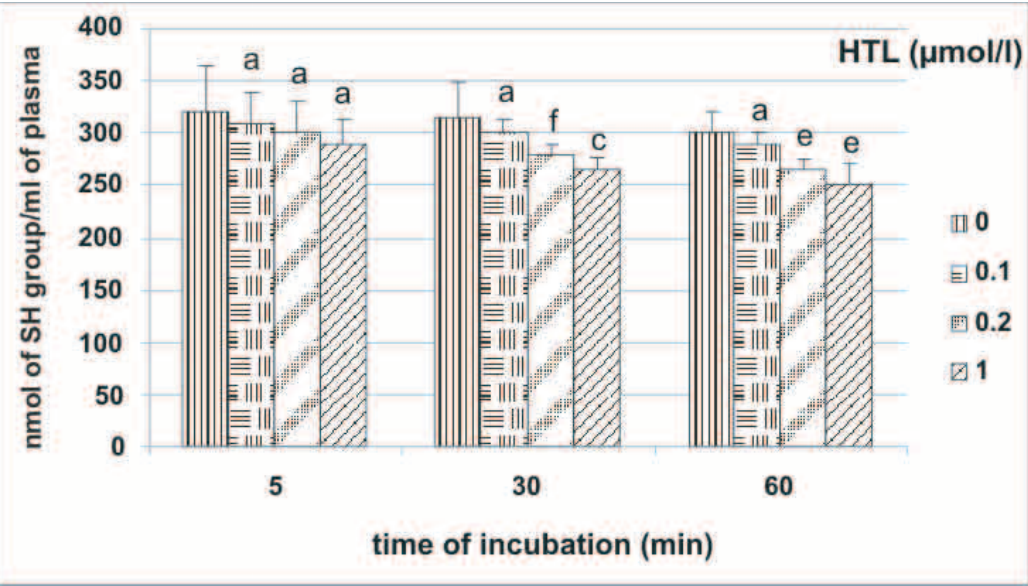

Figure 1. The effects of Hcys (A) and $\operatorname{HTL}(B)\left(5,30,60 \mathrm{~min} ; 37^{\circ} \mathrm{C}\right)$ on the level of thiol groups in plasma total proteins. Data represent means \pm SD of eight experiments. The statistically significant differences were performed with one-way ANOVA and the significance level was $p<0.05$. The effects were also statistically significant according to the unpaired Student's $t$-test: ${ }^{\mathrm{a}} p>0.05 ;{ }^{\mathrm{b}} p<0.05 ;{ }^{\mathrm{c}} p<0.01$; ${ }^{\mathrm{d}} p<0.002 ;{ }^{\mathrm{e}} p<0.001 ;{ }^{\mathrm{f}} p<0.02$; compared to control (plasma untreated with Hcys or HTL).

\section{Results}

Incubation of human plasma with Hcys $(10-100 \mu \mathrm{mol} / \mathrm{l})$ resulted in the changes of plasma proteins (Fig. 1A-3A). The level of thiol groups in total proteins after incubation of plasma (30 and $60 \mathrm{~min}$ ) with Hcys at the tested concentrations $(10-100 \mu \mathrm{mol} / \mathrm{l})$ was reduced (Fig. 1A). Figure $1 \mathrm{~A}$ shows the dose-dependent decrease of thiol groups in plasma total proteins treated with Hcys (for the incubation time 30 and 60 $\mathrm{min}$ ). The exposure of plasma (30 and $60 \mathrm{~min}$ ) to HTL resulted also in significant decrease of thiol amount in proteins (Fig. $1 B$ ). In the presence of HTL (at the highest tested concentration $1 \mu \mathrm{mol} / \mathrm{l}$, after incubation time $60 \mathrm{~min}$ ) the decrease of thiol groups was about $16 \%(p<0.001)$ (Fig. 1B).

The comparative studies demonstrated the reduction of free $\varepsilon$-amino groups of Lys in plasma proteins after 5, 30 or 60 min incubation of plasma with Hcys and HTL, and the ef- fects were dose-dependent (Fig. 2A and B). The longest used incubation time (60 min) of plasma with Hcys (at the highest tested concentration $100 \mu \mathrm{mol} / \mathrm{l})$ induced a decrease of free $\varepsilon$-amino groups of Lys in proteins about 25\% $(p<0.001)$ (Fig. 2A). We observed the same process, when plasma was treated with HTL $(1 \mu \mathrm{mol} / \mathrm{l}$, after incubation time $60 \mathrm{~min})$ $(p<0.001)$ (Fig. 2B).

We showed that Hcys or HTL (for the incubation time $60 \mathrm{~min}$ and at all tested concentrations) in vitro induced a decrease of carbonyl groups in plasma proteins, and the effect was dose-dependent (Fig. 3A and B). The highest tested concentration of Hcys $(100 \mu \mathrm{mol} / \mathrm{l}, 60 \mathrm{~min})$ or HTL (1 $\mu \mathrm{mol} / \mathrm{l}, 60 \mathrm{~min})$ caused the decrease of carbonyl groups in plasma proteins that reached about $24 \%(p<0.05)$ and $25 \%(p<0.05)$, respectively (Fig. 3A and B).

Table 1 shows that the prothrombin time was prolonged in plasma treated with Hcys or HTL when compared with the 
A
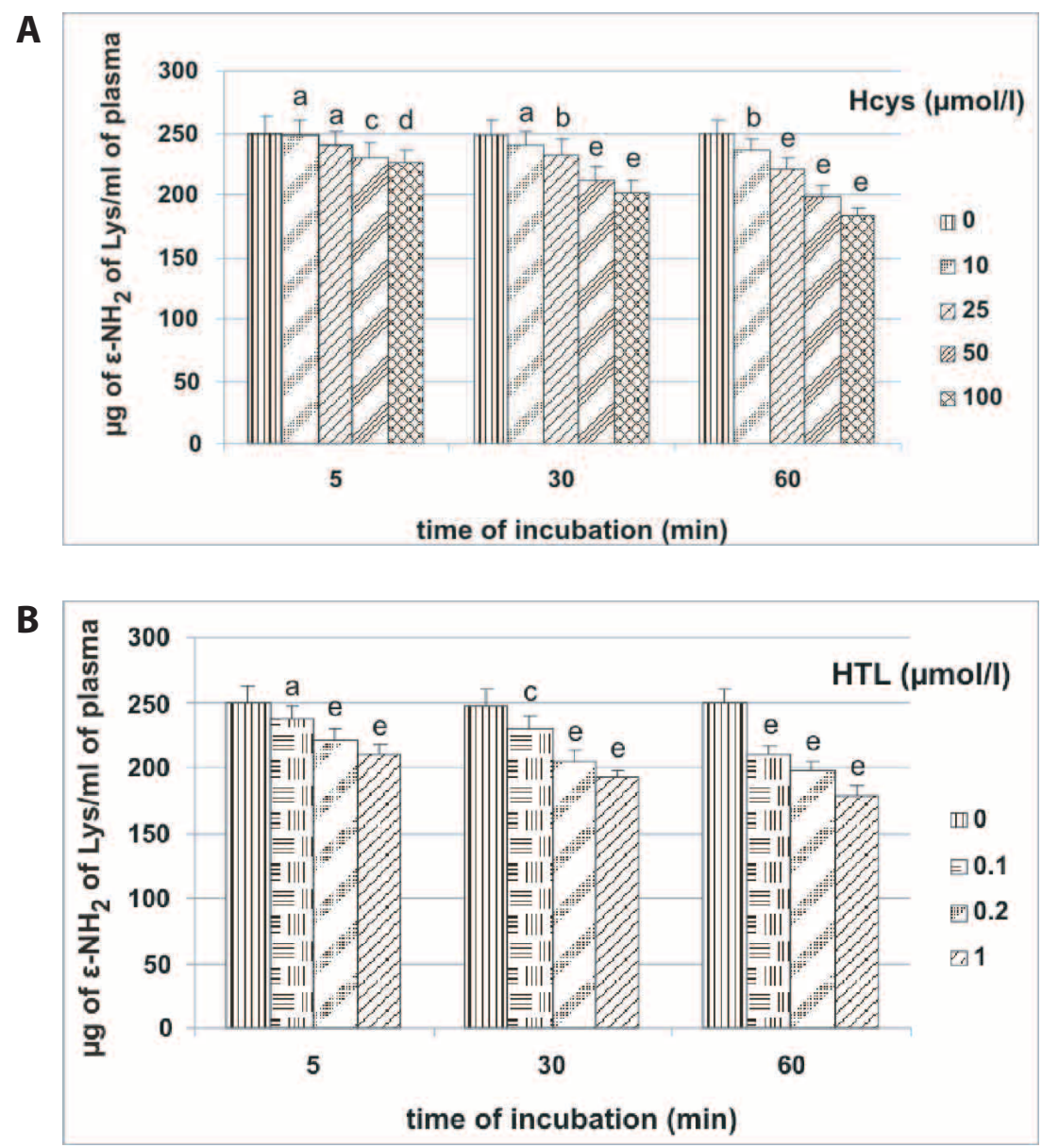

Figure 2. The effects of Hcys (A) and $\operatorname{HTL}(B)\left(5,30,60 \mathrm{~min} ; 37^{\circ} \mathrm{C}\right)$ on the level of $\varepsilon$-amino groups of Lys in plasma total proteins. Data represent means $\pm \mathrm{SD}$ of eight experiments. The statistically significant differences were performed with one-way ANOVA and the significance level was $p<0.05$. The effects were also statistically significant according to the unpaired Student's $t$-test: ${ }^{\mathrm{a}} p>0.05 ;{ }^{\mathrm{b}} p<0.05$; ${ }^{\mathrm{c}} p<0.01 ;{ }^{\mathrm{d}} p<0.002 ;{ }^{\mathrm{e}} p<0.001$; compared to control (plasma untreated with Hcys or HTL).

control. Hcys (at all tested concentrations) had no effect on thrombin time, but HTL prolonged the thrombin time.

\section{Discussion}

Hcys can be incorporated into protein molecules on one of two pathways: 1) translational pathway or 2) posttranslational pathway. In the first case, S-nitrosohomocysteine is necessary as an intermediate, which than is incorporated in polyamino acid chain. In the second case, conversion of Hcys to HTL occurs as a preliminary step to acylation of free $\varepsilon$-amino groups in proteins (Jakubowski 2001). $\varepsilon$-amino group of Lys is predominant $\mathrm{N}$-homocysteinylation place; however it could be also discovered on the C-terminal carboxy group or N-terminal amino group of protein (Hop and Bakhtiar 2002). If $\mathrm{N}$-homocysteinylation indeed takes place, reduction
Table 1. The prothrombin and thrombin time of plasma treated with Hcys and HTL $\left(30 \mathrm{~min} ; 37^{\circ} \mathrm{C}\right)$.

\begin{tabular}{lccc}
\hline & $\mathrm{c}_{\mathrm{s}}(\mu \mathrm{mol} / \mathrm{l})$ & Prothrombin time $(\mathrm{s})$ & Thrombin time $(\mathrm{s})$ \\
\hline control & - & $18.9 \pm 0.7$ & $59.1 \pm 1.2$ \\
\hline \multirow{4}{*}{ Hcys } & 10 & $23.2 \pm 0.9^{*}$ & $60.6 \pm 1.2^{* *}$ \\
& 25 & $24.4 \pm 1.2^{*}$ & $60.4 \pm 1.3^{* *}$ \\
& 50 & $25.6 \pm 1.0^{*}$ & $61.0 \pm 1.0^{* *}$ \\
HTL & 100 & $22.7 \pm 1.3^{*}$ & $60.5 \pm 0.6^{* *}$ \\
& 0.1 & $23.4 \pm 0.7^{*}$ & $65.4 \pm 1.0^{*}$ \\
& 0.2 & $23.8 \pm 1.7^{*}$ & $65.0 \pm 0.9^{*}$ \\
\hline
\end{tabular}

Data represent means \pm SD of eight experiments. The effect of four different concentrations of Hcys $(10,25,50$ and $100 \mu \mathrm{mol} / \mathrm{l})$ was statistically significant according to ANOVA I test, $p<0.05$ (for prothrombin time), $p>0.05$ (for thrombin time). The effect of three different concentrations of HTL $(0.1,0.2$ and $1 \mu \mathrm{mol} / \mathrm{l})$ was statistically significant according to ANOVA I test, $p<0.05$ (for prothrombin time and thrombin time). $c_{s}$, concentration of substance, control, without Hcys or HTL; Student's $t$-test (Hcys and/or HTLtreated plasma vs. control): ${ }^{*} p<0.001 ;{ }^{* *} p>0.05$. 
A
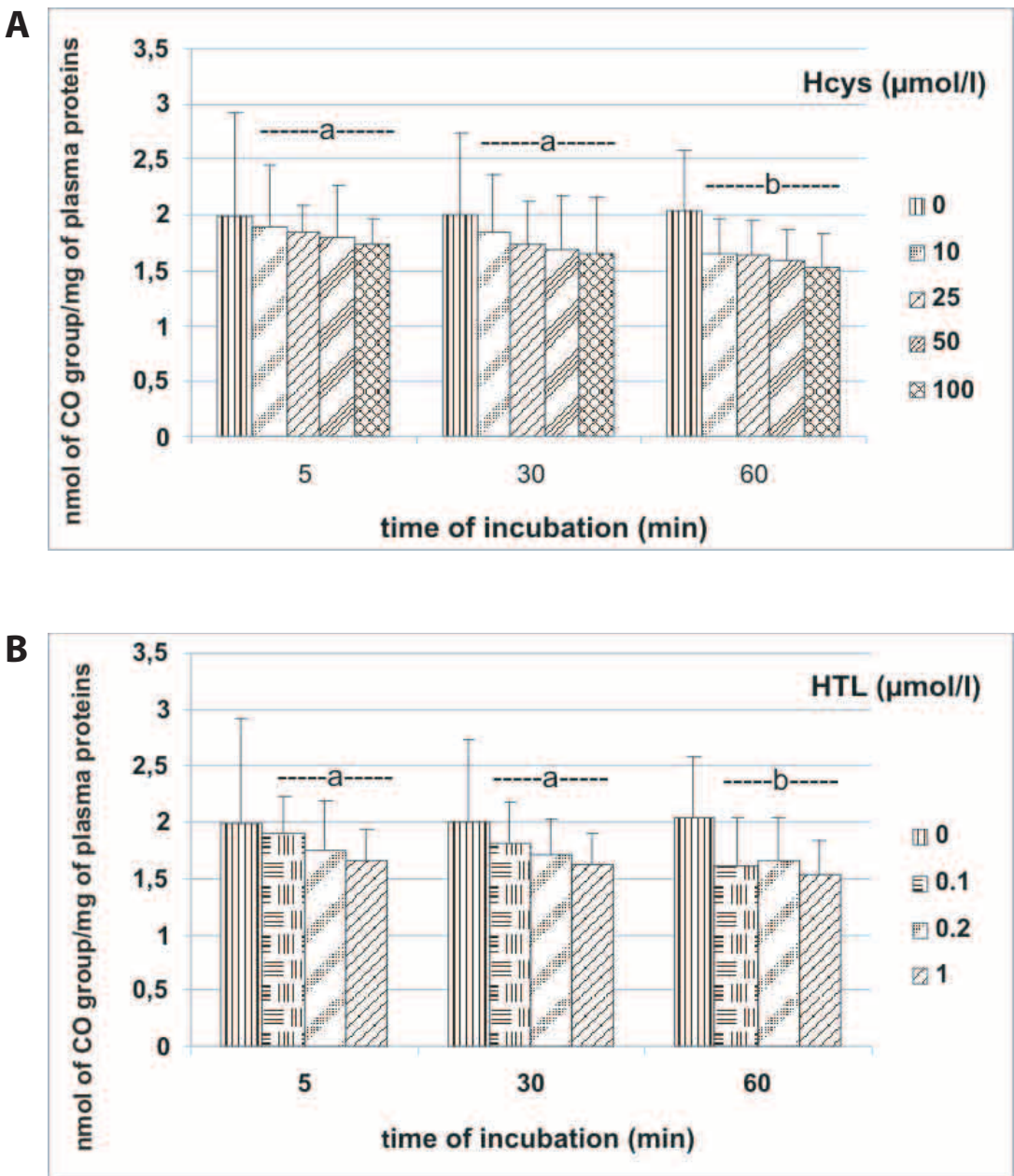

Figure 3. The effects of Hcys (A) and $\operatorname{HTL}(B)\left(5,30,60 \mathrm{~min} ; 37^{\circ} \mathrm{C}\right)$ on the level of carbonyl groups in plasma total proteins. Data represent means \pm SD of eight experiments. The statistically significant differences were performed with one-way ANOVA and the significance level was $p<0.05$. The effects were also statistically significant according to the unpaired Student's $t$-test: ${ }^{\mathrm{a}} p>0.05 ;{ }^{\mathrm{b}} p<0.05 ;$ compared to control (plasma untreated with Hcys or HTL).

in the number of free $\varepsilon$-amino groups should be expected. Here, we observed such reduction giving an evidence of $\mathrm{N}$-homocysteinylation of plasma proteins, during incubation of plasma not only with HTL, but also with the reduced form of Hcys (5-60 min) (Fig. 2A and B).

Mass spectrometric analysis of plasma fibrinogen, which is the main substrate for coagulation cascade and form a polymerized fibrin clot, treated with Hcys revealed twelve lysines that were homocysteinylated (Sauls et al. 2003, 2007; Undas et al. 2006; Sauls et al. 2007). Sauls et al. (2007) suggest that homocysteinylation of lysine residues in fibrinogen may be linked to three important functional consequences. First, modification in the $\mathrm{aC}$ domain could alter the lateral association of fibers and thereby alter clot structure. Second, the alteration of the protein conformation may interfere with calcium binding, which could contribute to alterations in fibrin clot structure. Third, modification of lysine sites that are directly involved in fibrinolytic enzyme binding and activity could lead to increased resistance to fibrinolysis - the process by which a fibrin clot is dissolved. Modification of fibrinogen induced by Hcys or HTL may be dependent on the alteration of its structure associated with changes of its haemostatic functions and the pathogenesis of different cardiovascular disorders, including thrombosis and atherosclerosis.

Next to acylation on $-\mathrm{NH}_{2}$ moiety induced by Hcys/ HTL, second posttranslational protein modification, named S-homocysteinylation, exists. It is result of disulphide bond formation between free thiol groups derived from protein cysteine or Hcys. It is known that such reaction occurs in vivo in humans and decreases the level of free thiols, 
reducing in that way a pool of reduced thiols (Rossi et al. 2008). The major components of the S-homocysteinylated protein pool in human plasma are albumin and $\gamma$-globulin (Sengupta et al. 2001). Binding of Hcys to plasma proteins is biphasic. First reaction, involving displacement of cysteine from plasma proteins, is rapid and oxygen independent, while the second reaction constitutes slower, oxygen-dependent thiol oxidation (Togawa et al. 2000). Our present results showed that not only the reduced form of Hcys, but also its cyclic thioester may diminish the amount of free protein thiol concentration, especially when blood plasma is exposed for a long incubation time $(60 \mathrm{~min}$ ) (Fig. 1A and B). However, Ferretti et al. (2006) observed increase in thiol content in LDL's (low density lipoproteins) taken from diabetic patients, but in theirs experiments hyperglycemia state could be responsible for this inconsistency. Moreover, we investigated total plasma proteins without any plasma fractionation.

For the first time, we found that Hcys and HTL reduce carbonyl concentration in total proteins of plasma (Fig. 3A and B). It may be probably due to direct reaction between thiol and carbonyl groups, because it was earlier shown in vitro that 1,3-thiazane-4-carboxylic acid is probably synthesized as a result of this reaction. Results of Wriston and Mackenzie (1957) and Jakubowski (2006) showed this product, which may be further metabolized (Wolen and Wriston 1963), but the properties of Hcys or HTL adducts with carbonyls have been unknown. We suggest that the reaction between Hcys/HTL and carbonyl groups in proteins and this process may be a new protein modification. Moreover, Hcys or HTL adducts with carbonyls may change protein structure with unknown physiological consequences. Our results that Hcys and HTL decrease the level of carbonyl groups are in agreement with other studies, where this process was observed in a model system (Jakubowski 2006), in human endothelial cells (Jakubowski et al. 2000), and in human blood platelets (Olas et al. 2008, 2009).

Modifications of many of the plasma proteins induced by Hcys or HTL may stimulate various functional changes, including enzyme inactivation, altered ligand binding, modified susceptibility to proteolytic degradation. For example, homocysteinylated molecules gain biotoxic features like LDL molecules, which after interaction with HTL can induce endothelial lipid peroxidation (Ferretti et al. 2004) or peroxynitrite production by human aortic endothelial cells (Ferretti et al. 2006). Coagulation factor Va is also S-homocysteinylated (Undas et al. 2001) and this modification could play a role in the modulation of hemostasis process. Clots formed from human plasma incubated in vitro with Hcys (at the high concentration $-3 \mathrm{mmol} / \mathrm{l}$ ) have been more compact structure, with shorter and more frequently branched fibers, than those formed in the absence of Hcys (Lauricella et al. 2002, 2006). Harpel et al. (1992) observed that Hcys $(<8 \mu \mathrm{mol} / \mathrm{l})$ enhances the binding of lipoprotein(a) to fibrin, and this results may suggest a biochemical relationship between thiol compound metabolism, thrombosis and atherogenesis. Our present studies reported that not only the reduced form of Hcys $(10-100 \mu \mathrm{mol} / \mathrm{l})$, but also HTL (at lower concentrations than Hcys) modulates the coagulation properties of human plasma (Table 1). The prolonged prothrombin time may imply that HTL decreased the coagulation properties of plasma proteins (Table 1). Moreover, Table 1 shows that the thrombin time was prolonged in plasma treated with HTL when compared with control. The obtained results are consistent with other experiments, in which rabbit plasma was treated with Hcys (Sauls et al. 2003). In this context, this process may suggest that Hcys and HTL may affect proteins of prothrombinase system and modulate the structure of coagulation factors: V, VII, X and prothrombinase. Moreover, in hyperhomocysteinemia the prothrombotic tendency may be related to impaired inactivation of S-homocysteinylated coagulation factor Va by activated protein C (Undas et al. 2001). However, Hcys and HTL have no effect on factor $\mathrm{V}$ activation by thrombin. Factor $\mathrm{V}$ incubated with $\left[{ }^{35} \mathrm{~S}\right]$ Hcys $(10-450 \mu \mathrm{M})$ incorporated label within $5 \mathrm{~min}$, which was found only in those fragments that contained free sulfhydryl groups: the light chain (Cys-1960, Cys-2113), the B region (Cys-1085), and the $26 / 28-\mathrm{kDa}$ (residues 507-709) activated protein C cleavage products of the heavy chain (Cys-539, Cys-585). Our earlier results indicate also that in blood platelets, which are involved in hemostasis process, the decrease of thiol groups in proteins treated with Hcys and HTL occurred (Olas et al. 2009). On the basis of these observations, we proposed that Hcys or HTL may act as an oxidant, because in our earlier other studies we have observed that platelet aggregation (induced by Hcys HTL) was associated with free radical production (Olas et al. 2008).

Moreover, there are not pharmacologically active compounds protecting plasma proteins from investigated modifications. Different compounds (folic acid, vitamins: $\mathrm{B}_{6}$ and $B_{12}$ ) present in human diet may have promising effect on the concentration of Hcys in human plasma. However, the results of Bogers et al. (2007) showed that the increased fruit and vegetable consumption may be insufficient to change plasma Hcys concentration.

In conclusion, our results strongly suggest that Hcys and HTL induced modifications of total plasma proteins. The consequence of these modifications ( $\mathrm{N}$ - and S-homocysteinylation) may be the alteration in plasma protein structure associated with changes of biological functions, and further studies should be carried out to investigate the possible role of these modifications in different diseases.

Acknowledgement. This work was supported by grant 506/810 from University of Lodz. 


\section{References}

Ando Y., Steiner M. (1973a): Sulfhydryl and disulfide groups of platelet membranes. II. Determination of sulfhydryl groups. Biochim. Biophys. Acta 311, 38-44; doi:10.1016/ 0005-2736(73)90252-6

Ando Y., Steiner M. (1973b): Sulfhydryl and disulfide groups of platelet membranes. I. Determination of disulfide groups. Biochim. Biophys. Acta 311, 26-37; doi:10.1016/00052736(73)90251-4

Bald E., Chwatko G., Glowacki R., Kusmierek K. (2004): Analysis of plasma thiols by high-performance liquid chromatography with ultraviolet detection. J. Chromatogr. 1032, 109-115; doi:10.1016/j.chroma.2003.11.030

Bogers R. P., Dagnelie P. C., Bast A., van Leeuwen M., van Klaveren J. D., van den Brandt P. A. (2007): Effect of increased vegetable and fruit consumption on plasma folate and homocysteine concentrations. Nutrition 23, 97-102; doi:10.1016/j.nut.2006.11.002

Boysen G., Brander T., Christensen H., Gideon R., Truelsen T. (2003): Homocysteine and risk of recurrent stroke. Stroke 34, 1258-1261; doi:10.1161/01.STR.0000069017.78624.37

Chwatko G., Jakubowski H. (2005a): The determination of homocysteine-thiolactone in human plasma. Anal. Biochem. 337, 271-277; doi:10.1016/j.ab.2004.11.035

Chwatko G., Jakubowski H. (2005b): Urinary extraction of homocysteine thiolactone in humans. Clin. Chem. 51, 408-415; doi:10.1373/clinchem.2004.042531

D'Angelo A., Selhub J. (1997): Homocysteine and thrombotic disease. Blood 90, 1-11

Ferretti G., Bacchetti T., Moroni C., Vignini A., Nanetti L., Curatola G. (2004): Effect of homocysteinylation of low density lipoproteins on lipid peroxidation of human endothelial cells. J. Cell. Biochem. 92, 351-360; doi:10.1002/jcb.20069

Ferretti G., Bacchetti T., Rabini R. A., Vignini A., Nanetti L., Moroni C., Mazzanti L. (2006): Homocysteinylation of low-density lipoproteins (LDL) from subjects with Type 1 diabetes: effect on oxidative damage of human endothelial cells. Diabet. Med. 23, 808-813; doi:10.1111/ j.1464-5491.2006.01809.x

Glowacki R., Wójcik K., Bald E. (2001): Facile and sensitive method for the determination of mesna in plasma by highperformance liquid chromatography with ultraviolet detection. J. Chromatogr. 914, 29-35; doi:10.1016/S00219673(00)01064-5

Harpel P. C., Chang V. T., Borth W. (1992): Homocysteine and other sulfydryl compounds enhance the binding of lipoprotein(a) to fibrin: a potential biochemical link between thrombosis, atherogenesis, and sulfydryl compound metabolism. Proc. Natl. Acad. Sci. USA 89, 10193-10197; doi:10.1073/pnas.89.21.10193

Harpel P. C., Zhang X., Borth W. (1996): Homocysteine and hemostasis: pathogenic mechanisms predisposing to thrombosis. J. Nutr. 126, S1285-1289

Hop C. E., Bakhtiar R. (2002): Homocysteine thiolactone and protein homocysteinylation: mechanistic studies with model peptides and proteins. Rapid Commun. Mass Spectrom. 16, 1049-1053; doi:10.1002/rcm.681
Jakubowski H. (1999): Protein homocysteinylation: possible mechanism underlying pathological consequences of elevated homocysteine levels. FASEB J. 13, 2277-2283

Jakubowski H., Zhang L., Bardeguez A., Aviv A. (2000): Homocysteine thiolactone and protein homocysteinylation in human endothelial cells: implications for atherosclerosis. Circ. Res. 87, 45-51

Jakubowski H. (2001): Protein N-homocysteinylation: implications for atherosclerosis. Biomed. Pharmacother. 55, 443-447; doi:10.1016/S0753-3322(01)00085-3

Jakubowski H. (2002): Homocysteine is a protein amino acid in humans. Implications for homocysteine-linked disease. J. Biol. Chem. 277, 30425-30428; doi:10.1074/jbc. C200267200

Jakubowski H. (2006): Mechanism of the condensation of homocysteine thiolactone with aldehydes. Chemistry 12, 8039-8043; doi:10.1002/chem.200600785

Lauricella A. M., Quintana I. L., Kordich L. C. (2002): Effects of homocysteine thiol group on fibrin networks: Another possible mechanism of harm. Thromb. Res. 107, 75-79; doi:10.1016/S0049-3848(02)00191-3

Lauricella A. M., Quintana I., Castanon M., Sassetti B., Kordich L. (2006): Influence of homocysteine on fibrin network lysis. Blood Coagul. Fibrinolysis 17, 181-186; doi:10.1097/01. mbc.0000220238.99843.45

Levine R. L., Wehr N., Williams J. A., Stadtman E. R., Shacter E. (2000): Determination of carbonyl groups in oxidized proteins. Methods Mol. Biol. 99, 15-24

Li Z., Sun L., Zhang H., Liao Y., Wang D., Zhao B., Zhu Z., Zhao J., Ma A., Han Y. (2003): Elevated plasma homocysteine was associated with hemorrhagic and ischemic stroke, but methylenetetrahydrofolate reductase gene C677T polymorphism was a risk factor for thrombotic stroke: a Multicenter Case-Control Study in China. Stroke 34, 2085-2090; doi:10.1161/01. STR.0000086753.00555.0D

Mansoor M. A., Svardal A. M., Ueland P. M. (1992): Determination of the in vivo redox status of cysteine, cysteinylglycine, homocysteine, and glutathione in human plasma. Anal. Biochem. 200, 218-229; doi:10.1016/00032697(92)90456-H

Olas B., Kedzierska M., Wachowicz B. (2008): Comparative studies on homocysteine and its metabolite - homocysteine thiolactone action in blood platelets in vitro. Platelets 19, 520-527; doi:10.1080/09537100802308081

Olas B., Kołodziejczyk J., Kedzierska M., Rywaniak J., Wachowicz B. (2009): Modification of human blood platelet proteins induced by homocysteine and its thiolactone in vitro. Thromb. Res. 124, 689-694; doi:10.1016/ j.thromres.2009.06.026

Perla-Kajan J., Twardowski T., Jakubowski H. (2007): Mechanisms of homocysteine toxicity in humans. Amino Acids 32, 561-572; doi:10.1007/s00726-006-0432-9

Ramakrishnan S., Sulochana K. N., Lakshmi S., Selvi R., Angayarkanni K. (2006): Biochemistry of homocysteine in health and diseases. Indian J. Biochem. Biophys. 43, 275-283

Ravaglia G., Forti P., Maioli F., Martelli M., Servadei L., Brunetti N., Porcellini E., Licastro F. (2005): Homocysteine and folate 
as risk factors for dementia and Alzheimer disease. Am. J. Clin. Nutr. 82, 636-664

Rossi R., Giustarini D., Milzani A., Dalle-Donne I. (2008): Cysteinylation and homocysteinylation of plasma protein thiols during ageing of healthy human beings. J. Cell. Mol. Med. 13, 3131-3140; doi:10.1111/j.1582-4934.2008.00417.x

Sashidhar R. B., Capoor A. K., Ramana D. (1994): Quantitation of epsilon-amino group using amino acids as reference standards by trinitrobenzene sulfonic acid. A simple spectrophotometric method for the estimation of hapten to carrier protein ratio. J. Immunol. Methods 167, 121-127; doi:10.1016/0022-1759(94)90081-7

Sauls D. L., Wolberg A. S., Hoffman M. (2003): Elevated plasma homocysteine leads to alterations in fibrin clot structure and stability: implications for the mechanism of thrombosis in hyperhomocysteinemia. J. Thromb. Haemost. 1, 300-306; doi:10.1046/j.1538-7836.2003.00053.x

Sauls D. L., Lockhart E., Warren M. E., Lenkowski A., Wilhelm S. E., Hoffman M. (2006): Modification of fibrinogen by homocysteine thiolactone increases resistance to fibrinolysis: a potential mechanism of the thrombotic tendency in hyperhomocysteinemia. Biochemistry 45, 2480-2488; doi:10.1021/bi052076j

Sauls D. L., Arnold E. K., Bell C. W., Allen J. C., Hoffman M. (2007): Pro-thrombotic and pro-oxidant effects of diet-induced hyperhomocysteinemia. Thromb. Res. 120, 117-126; doi:10.1016/j.thromres.2006.08.001

Sengupta S., Chen H., Togawa T., Di Bello P. M., Majors A. K., Budy B., Ketterer M. E., Jacobsen D. W. (2001): Albumin thiolate anion is an intermediate in the formation of albumin-
S-S-homocysteine. J. Biol. Chem. 276, 30111-30117; doi:10.1074/jbc.M104324200

Togawa T., Sengupta S., Chen H., Robinson K., Nonevski I., Majors A. K., Jacobsen D. W. (2000): Mechanisms for the formation of protein-bound homocysteine in human plasma. Biochem. Biophys. Res. Commun. 277, 668-674; doi:10.1006/bbrc. 2000.3723

Undas A., Williams E. B., Butenas S., Orfeo T., Mann K. G. (2001): Homocysteine inhibits inactivation of factor Va by activated protein C. J. Biol. Chem. 276, 4389-4397; doi:10.1074/jbc.M004124200

Undas A., Brozek J., Jankowski M., Siudak Z., Szczeklik A., Jakubowski H. (2006): Plasma homocysteine affects fibrin clot permeability and resistance to lysis in human subjects. Arterioscler. Thromb. Vasc. Biol. 26, 1397-1404; doi:10.1161/01.ATV.0000219688.43572.75

Wolen R. L., Wriston J. C. (1963): On the oxidation of D-1, 3 thiazane-4-carboxylic acid (D-tetrahydro-1,3-thiazine4-carboxylic acid). J. Biol. Chem. 238, 377-380

Wriston J. C., Mackenzie C. G. (1957): Synthesis and metabolism of 1,3-thiazane-4-carboxylic acid derived from formaldehyde and homocysteine. J. Biol. Chem. 225, 607-613

Zou C. G., Banerjee R. (2005): Homocysteine and redox signaling. Antioxid. Redox Signal. 7, 547-559; doi:10.1089/ ars.2005.7.547

Received: November 4, 2009

Final version accepted: February 5, 2010 